\section{The Impact of Artificial} intelligence and Robotics on the Future Employment Opportunities

\author{
Kamran Shaukat ${ }^{1,2 *}$, Farhat Iqbal ${ }^{2}$, Talha Mahboob Alam ${ }^{3}$, \\ Gagandeep Kaur Aujla', Liton Devnath', Abdul Ghaffar \\ Khan ${ }^{4}$, Rimsha Iqbal' ${ }^{2}$, Irum Shahzadi ${ }^{2}$ and Afifah Rubab ${ }^{2}$ \\ 'School of Electrical Engineering and Computing, The University of Newcastle, Callaghan, NSW 2308, \\ Australia \\ ${ }^{2}$ Punjab University College of Information Technology, University of the Punjab, Lahore 54590, \\ Pakistan \\ ${ }^{3}$ Department of Computer Science, University of Engineering and Technology, Lahore 54890, Pakistan \\ ${ }^{4}$ Department of Software Engineering University of Management and Technology Lahore
}

Received: 04 June, 2020

Accepted: 14 September, 2020

Published: 15 September, 2020

*Corresponding author: Kamran Shaukat, School of Electrical Engineering and Computing, The University of Newcastle, Callaghan, NSW 2308, Australia, E-mail:kamran.shaukat@uon.edu.au

Keywords: Artificial intelligence; Robotics; Nanotechnology; Employment opportunities; Healthcare; Security surveillance

https://www.peertechz.com

Check for updates

\begin{abstract}
The widespread human-robot interaction is increasing progressively as robots have made the life of everyone easy-going and comfortable. In this work, we have analysed the behaviour and characteristics of various types of robots. We have also studied the outgrowing relation between robotics and humans. In our analysis, we also have a selection of aspects of this field, which are done by the numerous technologists as well as scientists. We are interested in exploring the functioning of the human brain by generating a functioning system that resolves problems and gives satisfactory results. Artificial intelligence is a vast field that is also pushing its way in the domain of healthcare, business and quality assurance. Various researches disclose that the corporate sector is joining artificial intelligence to estimate the supply-demand concept and automate human resource systems. The public sector is also developing different intelligent machines for security surveillance and malfunction detection of critical systems like nuclear reactors. Artificial intelligence and robotics are also phenomenal to implement the law and order enforcement without any danger. As artificial intelligence is growing, employment in this domain is also increasing due to the high demand of intelligent machines in each sector worldwide. Our primary focus is to delve into the relationship between humans and robots.
\end{abstract}

\section{Introduction}

It is a well-recognized fact that Artificial Intelligence (AI) and robotics have been gaining a gigantic collaboration around the globe for several kinds of purposes. The escalating demand and prominence of the robotic have made life extremely easy. However, simultaneously an overly concerned hostility arises for human beings as the robots are taking over all the jobs in the industrial world. Robots are bringing about productivity while at the same time lessening the employment opportunities. Robots have already taken over all the bluecollar jobs. Now robots have started to enter white-collar jobs as well. As a result, jobs in all areas will be at stake. Robots, artificial friends, can perform low paid hard jobs in unsocial hours, generating a tremendous amount of comfort for the world. There is a high possibility that future generations will see robots as teachers and carers as soon as the robots are successfully learning feelings like compassion and complex response sensing. Robots perform jobs with faster speed as studies suggest that one robot functions similarly to 70 fulltime human workers [1]. The rise in robotic adoption results in falling into employment opportunities [2]. However, the next generations can only be able to achieve the fundamental advances of the robots after investing in this field for years[3].

We have done a systematic analysis of various kinds of robots by utilizing the comparison parameters to demonstrate 
the fundamental objective of the development of the robots. The main objective of our research is to expose the consequences of the robotics on human employment opportunities in all the areas. We have also discussed the future of the human and robot relationship.

\section{Advantages of automation and intelligent machines}

- Predominantly in the industries of developed countries (countries with high labor costs), automation and the use of production robots cause significant savings concerning the cost of labor and products. A production robot might thus cost cheaper than a worker in China. Another characteristic is that robots do not fall sick, have children or go on strikes and are not entitled to annual leaves.

- An intelligent machine need not rely on external components and can work unfailingly and continuously $24 / 7$, and it can work in danger zones. As an implication, its accuracy is greater than that of a human, and it cannot be side-tracked either by fatigue or by other external circumstances.

- While making crucial decisions, intelligent systems can be governed by unprejudiced standards so that decisions can be made practically, based on facts and data. Productivity expansions have so far always led to an upgrading of living circumstances for everybody. The same applies to intelligent machines.

- The significant advantage for employees is that the burden of labor-intensive may reduce for them; tedious, dull work can be done via self-ruling frameworks. The same is appropriate for typical back-end activities in the service sector: frameworks can be designed to gather information naturally, transfer data from one system to another, and find resolutions for problems. Once an interface between two systems is set up, manual intervention to enter data is not necessary.

- Apart from supporting functions, intelligent machines can be designed with life-saving capabilities as well, for example, robots used in medical diagnostics and inspection robots. These must be designed with high accuracy to avoid any accidents and to have the best results.

\section{Robots and robotics}

Robots: A robot is an intensive, influential machine. Automotive control is used to guide a robot. The main objective of the robots is to assist the world in daily routines. The actions that a robot can perform comprises of picking the objects, moving, and destroying them, and modify them as directed [4].

Robot operating system: The robot operating system is a unique, comprehensive and opensource operating system that is developed to control the robots. This system functions the same as the computer operating system. Functions of a robot operating system are:
- Management of the hardware components, processes, and memory.

- Management of the data merging, concurrency, and parallelism.

The extensive use of $\mathrm{AI}$ and provision of hidden reasoning algorithms [5].

Robotics: Robotics is a branch of AI [6]. The mechanical construction is the property of the robots, which is used to form or design a particular task. The power and control of machinery are handled by the electrical components present in the robots. What, when, and how a robot performs a task is controlled by the computer program built in the robot.

History of robots and robotics: Telemanipulators are machines that are controlled remotely and have an arm and a gripper. Humans use a control device to give instructions to telemanipulators. The main objective of the telemanipulators is to provide successful collaboration with the radioactive material. Numerical control provides the facility to control the machine accurately. In 1952 for the first time, numeric control was used by MIT. Numerical control caused the development of the APT (Automated, programmed tools). In 1961 the first industrial robot was developed using these techniques. Those robots were used in industrial jobs such as car construction plants. The desire for autonomous transport systems leads to the development of autonomous robots. Since 1975 the humanoid robots are being developed. MIT-AI-Lab has been developing humanoid robots named 'Cog' since 1994. Robots are the best friends of humans in science fiction. However, soon we will see the roles taking the jobs as universal programmable machine slaves [4].

Ai and robotics: Artificial intelligence is a vast field that is also pushing its way in the domain of healthcare [7], business [8] and social sector [9]. The concept of AI and robotics is based on an agent called an 'actor'. An actor is considered a software component, and it has a unique assembly of the hardware structure of the robot. The unique link between actor and physical structure of the robot enables the control of the robot through the actor. The software component uses sensors to read the data. After completing the reading process, the robot decides to take the next action and give directions to its effectors to act physically in the environment [6]. AI-Robotics intersection covers the following concerns:

- Actions that are planned, including the monitoring and the reasons behind the goal.

- Through open environments, we have modelling, understanding, and picking.

- Developing interaction with humans as well as other robots.

- Learning models that are required by the functions.

And combining those functions to develop a flexible and durable architecture [4]. 
Analysis of different robots: Gradually different types of robots have been invented. In Table I, we have provided a comparative study of various types of robots.

Human-robot interaction: HRI is human communication reliant [10]. In 1941 the author Isaac Asimov three significant laws of robotics: A robot should not attempt to injure a human being. The human gave any order, the robot must obey, except those orders which may create conflict with the first stated law. It is the responsibility of the robot to protect its existence, but that protection should not have a clash with the first two laws. These laws determine the idea of safe interaction. The growth of human-robot interaction can lead to human injury. In the modern world, this issue can be resolved by invalidating the sharing of workspace between human and robot workers at any time [10].

According to a prediction, in 2025, the robots will be hired for around 3.5 million jobs where there will be no good office jobs for people. According to the report of a foundation, in 2025, there will be no need for nursing carers for older people because robots will perform the caring duty. Japan will be able to save a budget of 2.1 trillion yen ( $\$ 21$ billion) that must be spent on insurance payments for elders. In 2030, Japan will be able to save 16 percent, depending on the number of jobs occupied by the robots. The law of human-human interaction also applies to human-robot interaction. The law states that companions with the same traits tend to communicate. Drawbacks of robots as carers include the feeling of isolation due to the lack of human attention, love, empathy, and care. Having no emotional interaction with the carer is odd. The goal of the HRI research is to achieve more effective and natural human-robot interaction to provide necessary guidance for robots [11].

The reason to choose robots for robot-human interaction instead of human-human interaction is that we can decide the level of association with a robot according to the requirement. Robots cannot perform a task unless we direct them to do so. These characteristics prove the robot as the right partner.

If the decoding of intentions behind the instructions from human teachers is possible, then it is straightforward for us to teach a robot that how to 'understand' a natural language, and after that, it can build enough knowledge using that language. This leads us to a stage where we can get a robot that is smart enough as those babies who learn much better practically when they are taught. It is highly required to effectively build human-robot interaction so robots can respond to humans more effectively and acceptably. According to HRI, the main goal is to achieve human satisfaction, comfort and confidence in their surroundings. Everyday human-robot communication, using emotions for the recognition, learning from reactions, and delivering effective responses, accordingly, are the main challenges [10].

\section{Future of the jobs with the existence of robotics}

Respondents were asked to share their perspectives and insights on their greatest fears for their profession to 2025 . The respondents stated that there would be an increment in unemployment, and people will have to involve in more and more technology learning. World Economic Forum (WEF) provided a new report that has arranged its yearly meeting in Davis' Swiss ski resort, factories and hospitals say that in the next 5 years the robots will take over 5.1 million office jobs. According to a survey conducted by young workers in the western countries, they considered that they could not perform their jobs appropriately by only relying on their education as their qualifications do not prepare them to attain it. The job skills gap between humans and robots is primarily observed in Europe. According to a survey, around $80 \%$ of people stated that it is highly needed to learn advanced technical skills, other than the school syllabus, to keep pace with the advancements in robotics[12].

Fourth industrial revolution millions of jobs at risk: According to a report on the future of jobs, in each industry, there will be an exceedingly high impact of robotics, and jobs will be replaced. At the same time, the demand for skilled workers will be on a high peak, which may include specialist sales representatives and data analysts. According to the report, this robotic revolution will put the jobs of the women at higher risk as the prominent roles performed by the women are low growth, sales jobs, or administrative roles [12]. The industrial sector has already been revolutionized by automation and robotization over the last 40 years, which has raised productivity but also caused unemployment. In 1980, the manufacturing jobs reached their peak in the United States, also with low wages in the middle class. At the time, the current counting of industrial robots is 20,000 in the country, and this counting is going to increase day by day. In the United States, in the coming 25 years, $10 \%$ of the jobs that are related to

Table 1: Analysis of Different Types of Robot.

\begin{tabular}{|c|c|c|c|c|c|}
\hline Criterion/Robot Types & Swarm robotics & Nanorobotics & ASIMO robotics & TOPIO robotics & Autonomous robotics \\
\hline Population Size & High range of Variation & $\begin{array}{l}\text { High range of } \\
\text { Variation }\end{array}$ & $\begin{array}{l}\text { Maybe a single robot or } \\
\text { Variation in a great range }\end{array}$ & $\begin{array}{l}\text { Maybe a single robot or } \\
\text { Variation in a great range }\end{array}$ & $\begin{array}{c}\text { Maybe a single robot or Variation } \\
\text { or fixed in a great range }\end{array}$ \\
\hline Control & $\begin{array}{l}\text { Decentralized and } \\
\text { autonomous }\end{array}$ & Autonomous & Autonomous & $\begin{array}{l}\text { Computer control through the } \\
\text { wrist of the robot }\end{array}$ & Autonomous \\
\hline Homogeneity & Homogeneous & Homogeneous & $\begin{array}{l}\text { Homogeneous or } \\
\text { heterogeneous }\end{array}$ & Homogeneous & Homogeneous or heterogeneous \\
\hline Flexibility & High & High & High & High & High \\
\hline Scalability & High & High & High & High & High \\
\hline Environment & Unknown & Known & Known & Known & Known or unknown \\
\hline Motion & Yes & Yes & Yes & Yes & Yes \\
\hline
\end{tabular}


driving will be finished because the trend of driverless cars will be on a high peak. According to a computer science professor at Cornell University named Bart Selma, in the next 2 to 3 years, our society will see autonomous robots [13].

At the McKinsey Global Institute, a partner Michael Chui, during a board on 'Is Any Job Truly Safe?' stated that robots provide high-quality work with low error rates. Still, it can diminish the number of labours. More than 700 speakers said that low-wage, low-skill jobs had been done away due to the technology revolution. In some mines of Australia, robot operating trucks are cited; employees are replaced with corporate legal action software, which has the advancements to shift thousands of documents before trials from one place to another; and on Fence Street, the computerization of essential jobs. Goldman Sachs Group, who is the organizer of a financial services analytics company, chief executive of Kensho, Daniel Nadler, stated that all the jobs related to moving data spreadsheets would be automated in the next years. As bound trading is giving less profit to the businesses; hence, there is a considerable strain from the investors to increase the gain. Hence banks are increasingly moving towards automation to increase revenue[14].

Changing landscape of employment: It is essential to understand what will be the scenario where jobs are automated, and machines become smarter. Despite popular belief, mass unemployment will not be a resultant; however, a massive makeover of jobs seems likely [15]. Key trends will be as follows:

Technology reshapes every job: A broad scope of whitecollar and knowledge-worker jobs such as HR staff, legal staff, and even salespeople and marketers are defenseless against disturbance by robots and AI [16]. A more prominent chance to upgrade efficiency may lie in re-examining and rethinking work around tackling business issues, providing new services, and achieving new levels of productivity and worker satisfaction and passion [17].

Rise of more social jobs: Research recommends that in excess of 30 percent of lucrative new employments will be social and 'basically human' in nature [15]. In this view, employers should become much more focused on exploring opportunities to create work that exploits particularly human capacities, for example, interest, creative ability, imagination, and social and passionate knowledge.

Alternative work arrangements: Innovation is changing more than the way jobs are done-it is changing the way organizations discover work. Numerous worldwide organizations, as of now, effectively utilize crowdsourcing platforms to source new thoughts, take care of issues, and plan complex frameworks [15].

Lifelong learning and skill development: As rapid technological and marketplace changes contract the valuable life expectancy of skills, specialists should move from gaining particular aptitudes and certifications to seeking after persevering and necessary abilities for long-lasting learning [15].

\section{Literature review}

Lewicki, et al. [1] stated that the automation technologies had been speedily replacing all the manual jobs. Robots have already seized most of the blue-collar jobs, and currently, they are also taking over white-collar jobs. Frishberg [18] underlined the escalating demand for cutting-edge robots that can perform hazardous jobs because of the dearth of low-wage agricultural and mining workers. Belanche, et al. [19] provided empirical insight into the expanding demand for organizational robots. The results showed that if a service failure occurs because of a human worker, then the customers set the malfunction responsibility on the worker. Whereas, if a robot provides a botched service, then the organization is most likely to get blamed, not the robot who was performing that job. Vries, et al. [2] assessed the relationship between the rise of robotics adoption and the fall of job vacancies by using the ten (2005-2015) years data from 37 different economies. The findings showed that the rise of the adoption of automation and robotics significantly causes a collapse in employment opportunities. Jackson, et al. [20] evaluated the social impact of robotics in the workplace environment by taking a hypothesis under analysis that increased usage of robotics can reduce prejudice at the workplace. The study suggested that salience of robotics reduces intergroup social and religious prejudices.

\section{Conclusion}

Self-ruling robots are confronting an assortment of open situations, and differing qualities of assignments are incapable of depending on the primary leadership abilities of a human designer. There is a need for showing the complexity of thinking capacities required to comprehend their surroundings and present surroundings and to perform deliberately. In the paper, we have alluded to such thinking abilities as pondering capacities, firmly consistent inside a mind-boggling design. We have introduced an outline of the best in class for some of them. With the end goal of this review, we have suggested that it was illuminating to recognize these capacities as for their primary part and computational prerequisites: the objective thinking, arranging, acting, and observing capacities. Be that as it may, let us demand once more: the fringe between them is not fresh. The objective for their execution inside operational engineering needs to consider various prerequisites, specifically a chain of command of shut circles, from the most element inward circle, nearest to the tactile engine flags and summons, to the most 'offine' outer circle.

\section{References}

1. Lewicki P, Tochowicz J, van Genuchten J (2019) Are robots taking our jobs? A RoboPlatform at a bank. IEEE Software 36: 101-104. Link: https://bit.ly/33mkutw

2. de Vries GJ, Gentile E, Miroudot S, Wacker KM (2020) The rise of robots and the fall of routine jobs. Labour Economics 66: 101885. Link: https://bit.ly/3htXhun

3. Chung JH, Lee YS () The Evolving Impact of Robots on Jobs.

4. Ingrand F, Ghallab M (2014) Robotics and artificial intelligence: A perspective on deliberation functions. Al Communications 27: 63-80. Link: https://bit.ly/2FqJJD2 
5. Quigley M, Conley K, Gerkey B, Faust J, Foote T, et al. (2009) ROS: an opensource Robot Operating System. In ICRA workshop on open source software 5. Link: https://bit.ly/2FEAaQs

6. Niemueller T, Widyadharma S (2003) Artificial intelligence-an introduction to robotics. Link: https://bit.ly/3bY60UD

7. Latif MZ, Shaukat K, Luo S, Hameed IA, Iqbal F, et al. (2020) Risk Factors Identification of Malignant Mesothelioma: A Data Mining Based Approach. In 2020 International Conference on Electrical, Communication, and Computer Engineering (ICECCE) 1-6. Link: https://bit.ly/3c7Yu9X

8. Alam TM, Shaukat K, Mushtaq M, Ali Y, Khushi M, et al. (2020) Corporate Bankruptcy Prediction: An Approach Towards Better Corporate World. Computer Journal. Link: https://bit.ly/35ARSiW

9. Alam TM, Awan MJ (2008) Domain Analysis of Information Extraction Techniques. Link: https://bit.ly/2RoNFqf

10. Goodrich MA, Schultz AC (2008) Foundations and Trends ${ }^{\circledR}$ in HumanComputer Interaction. Foundations and Trends ${ }^{\circledR}$ in Human-Computer Interaction 1: 203-275.

11. Alenljung B, Lindblom J, Andreasson R, Ziemke T (2019) User experience in social human-robot interaction. In Rapid automation: Concepts, methodologies, tools, and applications, ed: IGI Global. 1468-1490.

12. Skilton M, Hovsepian F (2017) The $4^{\text {th }}$ industrial revolution: Responding to the impact of artificial intelligence on business: Springer. Link: https://bit.ly/3mmzD6E
13. Tan Y, Zheng ZY (2013) Research advance in swarm robotics. Defence Technology 9: 18-39. Link: https://bit.ly/2RpKIG8

14. West DM (2015) What happens if robots take the jobs? The impact of emerging technologies on employment and public policy. Centre for Technology Innovation at Brookings, Washington DC. Link: https://brook.gs/2Zz1gQr

15. Sagara H, Das K (2020) Technological Disruptions and the Indian IT Industry: Employment Concerns and Beyond. In Digitalisation and Development ed: Springer 119-143. Link: https://bit.ly/2GZO2FR

16. Hagel J, Schwartz J, Bersin J (2017) Navigating the future of work. Deloitte Rev 21: 27-45. Link: https://bit.ly/3hv20RA

17. Acemoglu D, Restrepo P (2018) Artificial intelligence, automation and work National Bureau of Economic Research. Link: https://bit.ly/3bXRtZe

18. Frishberg M (2020) Robots and Al Take on Dirty Jobs. Research-Technology Management 63: 2. Link: https://bit.ly/3ivV179

19. Belanche D, Casaló LV, Flavián C, Schepers J (2020) Robots or frontline employees? Exploring customers' attributions of responsibility and stability after service failure or success. Journal of Service Management. Link: https://bit.ly/3ho0Zpq

20. Jackson JC, Castelo N, Gray K (2020) Could a rising robot workforce make humans less prejudiced?. American Psychologist. Link: https://bit.ly/33ueJtE
Discover a bigger Impact and Visibility of your article publication with

Peertechz Publications

\section{Highlights}

* Signatory publisher of ORCID

* Signatory Publisher of DORA (San Francisco Declaration on Research Assessment)

* Articles archived in worlds' renowned service providers such as Portico, CNKI, AGRIS, TDNet, Base (Bielefeld University Library), CrossRef, Scilit, J-Gate etc.

* Journals indexed in ICMJE, SHERPA/ROMEO, Google Scholar etc.

* OAI-PMH (Open Archives Initiative Protocol for Metadata Harvesting)

* Dedicated Editorial Board for every journal

* Accurate and rapid peer-review process

* Increased citations of published articles through promotions

* Reduced timeline for article publication

Submit your articles and experience a new surge in publication services (https://www.peertechz.com/submission).

Peertechz journals wishes everlasting success in your every endeavours.

Copyright: ( 2020 Shaukat K, et al. This is an open-access article distributed under the terms of the Creative Commons Attribution License, which permits unrestricted use, distribution, and reproduction in any medium, provided the original author and source are credited. 